Kumawula, Vol. 1, No.2, Agustus 2018, Hal 120 - 130 DOI:http://10.24198/kumawula.v1i2.20836

ISSN 2620-844X (online)

Tersedia online di http://jurnal.unpad.ac.id/kumawula/index

\title{
PENINGKATAN KEPEDULIAN STAKEHOLDER PEMBANGUNAN DALAM MENCEGAH STUNTING DI DESA CANGKUANG WETAN KECAMATAN DAYEUHKOLOT KABUPATEN BANDUNG
}

\author{
Ida Widianingsih $^{1 *}$, Budhi Gunawan ${ }^{2}$, Binahayati Rusyidi ${ }^{3}$ \\ 1,2,3Pusat Studi Desentralisasi dan Pembangunan Partisipatif, Fisip Unpad \\ *ida.widianingsih@unpad.ac.id
}

\begin{abstract}
This article describes the efforts of increasing the awareness of the development stakeholders at the village level in order to prevent stunting in Cangkuang Wetan Village, Dayeuhkolot Sub District, Bandung Regency as a form of community service that has been integrated with the research of Unpad lecturers and also Unpad Students. Stunting is a national strategic issue that can be observed in many regions of Indonesia, which in turn pushes the goverment to implement prevention efforts. This article mainly uses the qualitative research method with many participatory techniques, which include observations, interviews, FGD's, and socialization. The activities was around 7 months long and started with field research preparation, issue mapping, activity planning, and socialization of the importance of stopping stunting to the Village Development Stakeholders. The team found that the Village Apparatus, the locals that work at the Posyandu, mothers of Balita, and also the Balita were very active and enthusiastic during the socialization process. However, there are still many obstacles in the efforts to prevent stunting that should be overcome through a more comprehensive and integrated with the development plan of the village in order to achieve a more optimal result.
\end{abstract}

Keywords: development Stakeholders, Stunting, Cangkuang Wetan Village, Bandung Regency

\section{THE INCREASED AWARENESS OF THE DEVELOPMENT STAKEHOLDER IN ADDRESSING STUNTING IN CANGKUANG WETAN VILLAGE, DAYEUHKOLOT SUB-DISTRICT, BANDUNG REGENCY}

\begin{abstract}
ABSTRAK
Artikel ini menjelaskan upaya meningkatkan kepedulian Stakeholders pembangunan tingkat Desa dalam mencegah Stunting di Desa Cangkuang Wetan, Kecamatan Dayeuhkolot, Kabupaten Bandung sebagai kegiatan Pengabdian Kepada Masyarakat yang diintegrasikan dengan riset Dosen dan KKN mahasiswa Unpad. Stunting merupakan isu strategis nasional yang terjadi di berbagai wilayah di Indonesia dan mendorong pemerintah untuk melaksanakan berbagai kegiatan upaya pencegahan. Kegiatan ini secara umum menggunakan pendekatan kualitatif dengan berbagai teknik partisipatif, seperti observasi, wawancara, FGD, dan sosialisasi. Kegiatan yang dilakukan selama kurang lebih 7 (tujuh) bulan diawali dengan persiapan lapangan, pemetaan isu, perencanaan kegiatan dan sosialisasi kepada stakeholder pembangunan desa terkait pentingnya menanggulangi stunting. Tim menemukan antusiasme dan peran aktif aparat desa, pegawai Puskesmas, tokoh masyarakat penggerak Posyandu, ibu Balita dan Balita dalam kegiatan sosialisasi yang dilakukan. Namun demikian, masih ada berbagai tantangan dalam upaya menangani stunting yang sebaiknya dilakukan dengan cara lebih komprehensif dan terintegrasi dengan perencaan pembangunan di Desa agar hasilnya lebih optimal.
\end{abstract}

Keywords: Stakeholders pembangunan, cegah Stunting, Desa Cangkuang Wetan, Kabupaten Bandung 


\section{PENDAHULUAN}

Perkembangan wilayah metropolitan tidak hanya menimbulkan dampak positif terkait dengan integrasi aktivitas ekonomi antar wilayah otonom, namun dapat mendorong terjadinya urban sprawl yang disertai dengan tidak meratanya kesejahteraan masyarakat dan perbedaan akses pelayanan publik antara wilayah pusat perkotaan dengan daerah pinggiran (Firman, 2002; Howell-Moroney, 2008; Hudalah, Winarso, \& Woltier, 2007). Dalam konteks pertumbuhan wilayah metropolitan di Indonesia, McGee mengemukakan adanya kecenderungan terbentuknya wilayah desakota yang secara geografis terletak pinggiran kota. Wilayah desakota tersebut kerapkali dihadapkan pada berbagai permasalahan terkait perubahan lingkungan seperti kualitas air maupun polusi (McGee, 2009).

Berbagai riset menemukan perubahan lingkungan di kawasan metropolitan berdampak pada tingginya kesenjangan social ekonomi masyarakat dan buruknya akses terhadap pelayanan public (Black et al., 2013; Dehghan et al., 2014; Gross, 2002; Prendergast \& Humphrey, 2014; Van De Poel, Hosseinpoor, Speybroeck, Van Ourti, \& Vega, 2008). Secara umum indicator tingginya kesenjangan social di negara-negara berkembang terlihat dari jumlah anak yang kekurangan gizi (stunting), pada tahun 2013 misalnya, tercatat 161 juta anak di dunia menderita stunting (Black et al., 2013; Van De Poel et al., 2008). Stunting pada berbagai Negara di dunia menjadi penyebab rendahnya pertumbuhan ekonomi dan produktivitas pasar kerja yang ditunjukkan oleh hilangnya 11\% GDP (Gross Domestic Products), hilangnya kesempatan memperoleh pendapatan pekerja dewasa sampai dengan 20\% (Sekretariat wakil presiden republik indonesia, 2017)

Di Indonesia sendiri, stunting merupakan problem kesehatan yang cukup serius, data Tim Nasional Percepatan Penangulangan Kemiskinan (TNP2K), menunjukkan bahwa 37\% anak dibawah usia 5 tahun di Indonesia menderita stunting. Mereka tidak hanya berasal dari kelompok masyarakat termiskin, namun kasusnya terjadi pada anak-anak yang berasal dari berbagai tingkat kesejahteraan social (Sekretariat Wakil Presiden Republik Indonesia, 2017; Tim Nasional Percepatan Penanggulangan Kemiskinan Republik Indonesia, 2018). 
Gambar 1. Stunting di Seluruh Indonesia berdasarkan Kelompok Pendapatan (2007-2013) dan 15 wilayah Indonesia dengan Prevalensi Stunting Tertinggi tahun 2013

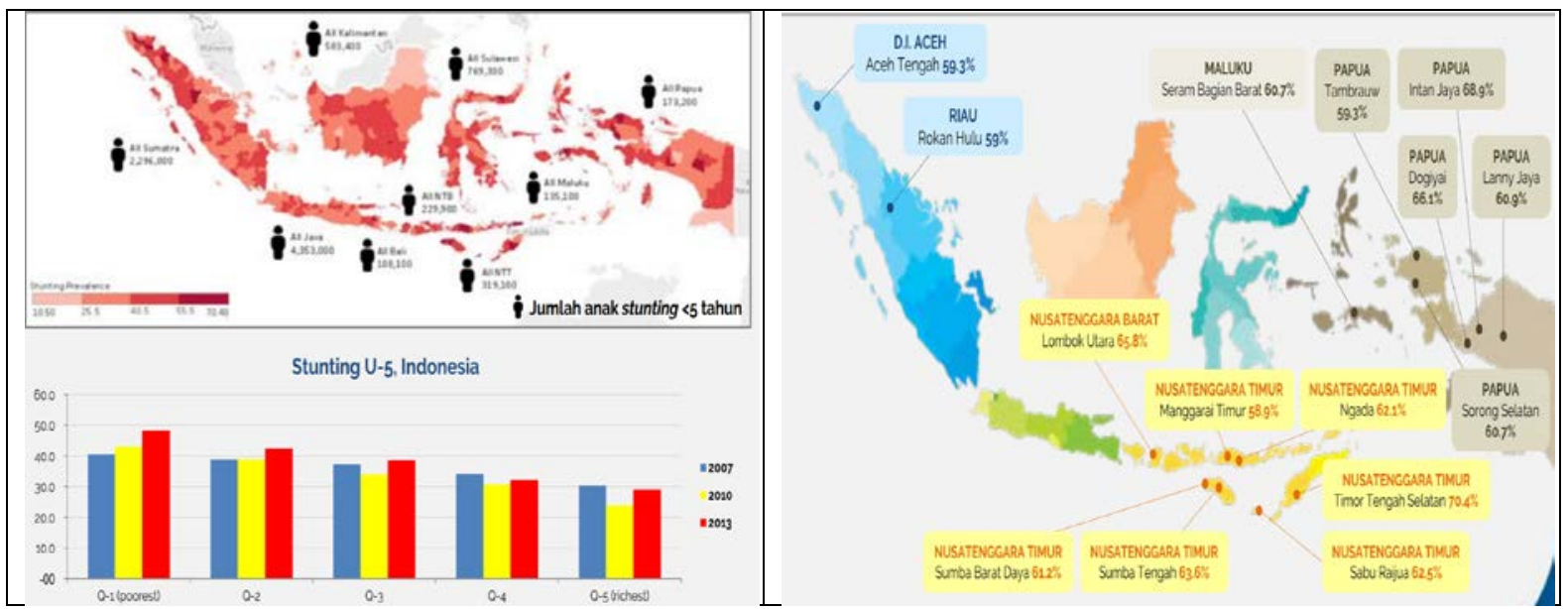
2018)

Sumber:(Tim Nasional Percepatan Penanggulangan Kemiskinan Republik Indonesia,

Pemerintah Indonesia dibawah arahan Presiden dan Wakil Presiden mencanangkan Gerakan Nasional Mencegah Stunting pada medio 2017 yang langsung dikoordinasikan Menko PMK dan melibatkan beberapa kementrian, seperti: Menteri Kesehatan, Menteri PUPR, Menteri PPN/Kepala Bappenas, Menteri Dalam Negeri, dan Menteri Kominfo. Gerakan Nasional Mencegah Stunting tersebut dilakukan dengan mengacu pada 5 Pilar Utama sebagai berikut:

Gambar 2. Pilar dan Konvergensi Penanganan Stunting di Indonesia

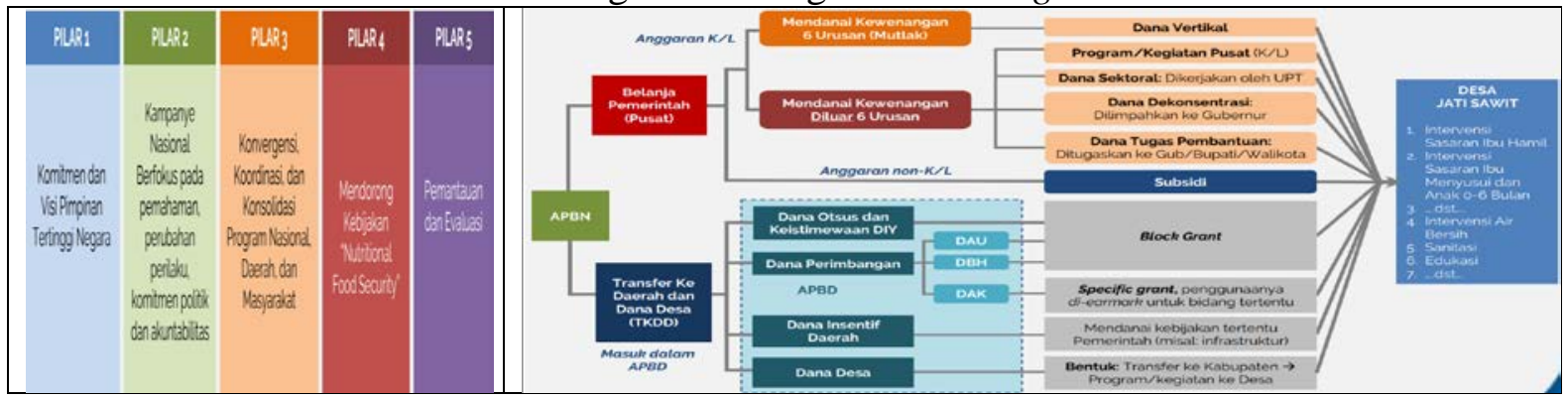
2018)

Sumber: (Tim Nasional Percepatan Penanggulangan Kemiskinan Republik Indonesia,

Berdasarkan data TNP2K, pemerintah menentukan 160 Kabupaten/Kota prioritas penanganan Stunting, Kabupaten Bandung merupakan wilayah prioritas. Dinas Kesehatan provinsi Jawa Barat mencatat 29,2\% anak mengalami Stunting, posisi ini menunjukkan pentingnya pemerintah daerah melakukan penanganan stunting secara komprehensif (Pikiran Rakyat 2018). 
Gambar 3. 160 Wilayah Prioritas Penanganan Stunting di Indonesia

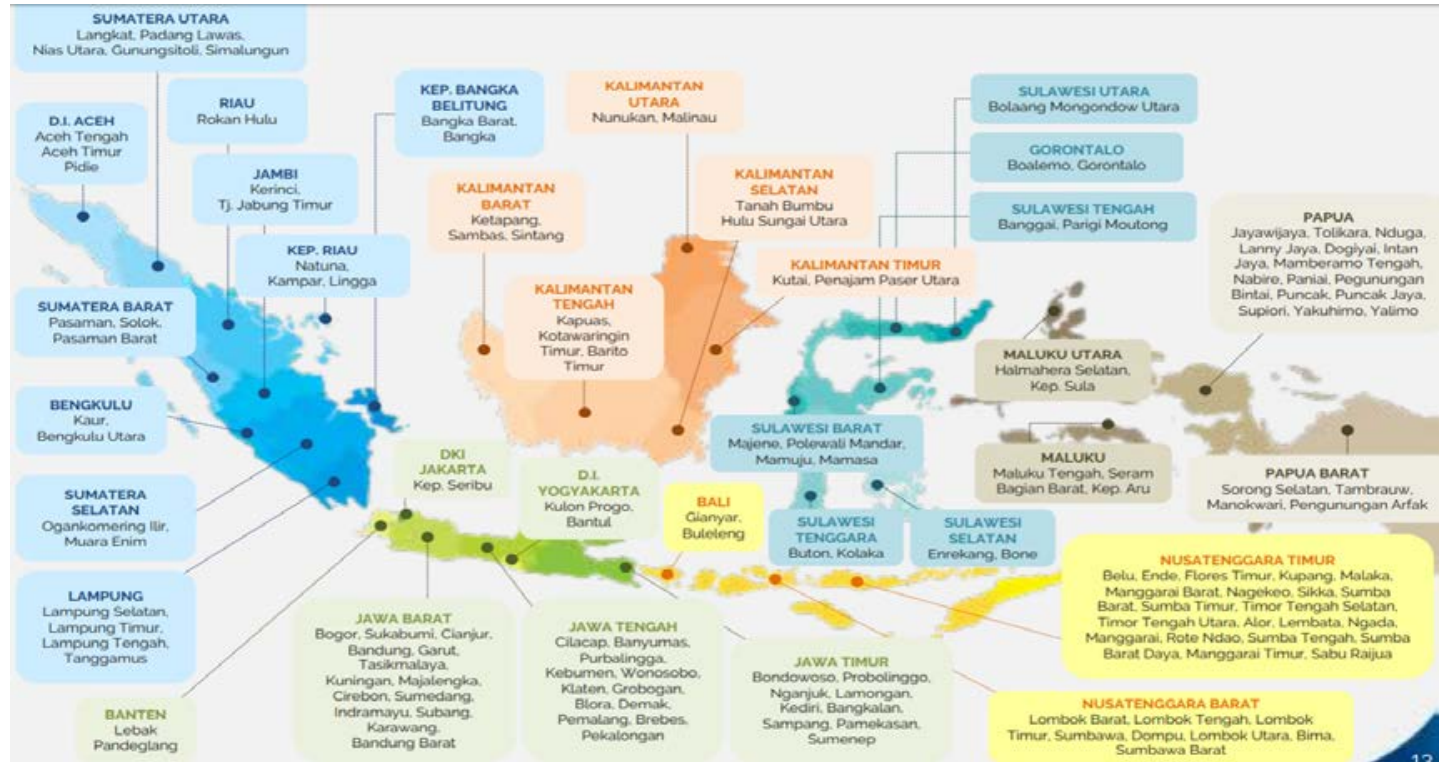
2018)

Sumber: (Tim Nasional Percepatan Penanggulangan Kemiskinan Republik Indonesia,

Kegiatan Pengabdian Kepada Masyarakat yang dilakukan di Desa Cangkuang Wetan, Kecamatan Dayeuhkolot, Kabupaten Bandung sebagai wilayah perbatasan antara Kota dan Kabupaten Bandung. Desa Cangkuang Wetan pernah dijadikan lokasi kegiatan Pemberian Makanan Tambahan (PMT) oleh Presiden Jokowi dan Gubernur Jawa Barat pada bulan September 2016 (Pikiran Rakyat 2018).

Berdasarkan arahan dari DRPM Universitas Padjadjaran, kegiatan PPM ini diintegrasikan dengan kegiatan KKN (Kuliah Kerja Nyata) Mahasiswa Unpad Semester Ganjil 2018/2019. Untuk menyelenggarakan amanah Peraturan Pemerintah Nomor 51 Tahun 2015 tentang Statuta Universitas Padjadjaran pasal 6, bahwa Universitas Padjadjaran harus menyelenggarakan pengabdian kepada masyarakat untuk memberikan kontribusi dalam memajukan kesejahteraan umum dan mencerdaskan kehidupan bangsa dengan arah dan tahapan yang jelas, maka penyelenggaraan PPM di Universitas Padjadjaran akan terintegrasi dengan kegiatan pendidikan dan penelitian.

Program pengabdian kepada masyarakat merupakan upaya peningkatan dan pengembangan bersama antara peneliti, masyarakat lokal dan pemerintah daerah serta pemangku kepentingan lainnya dalam rangka membantu masyarakat dan stakeholder pembangunan terkait untuk lebih memahami pentingnya tindakan intervensi ini guna menghindari stunting yang dialami oleh anak sebagai masa depan bangsa. Kegiatan ini diarahkan pada pemahaman mengenai urgensi dalam mengurangi angka gizi buruk dan meningkatkan kesehatan baik ibu hamil, balita, dan anak-anak, sebagai salah satu langkah 
pelaksanaan Tujuan Pembangunan Berkelanjutan (SDGs) sesuai dengan Peraturan Presiden Nomor 59 Tahun 2017 yaitu menjamin kehidupan yang sehat dan meningkatkan kesejahteraan seluruh penduduk semua usia (Peraturan Presiden Nomor 59, 2017).

\section{METODE}

Sebagaimana dijelaskan sebelumnya, kegiatan PPM ini merupakan bagian dari riset Dosen Unpad dan diintegrasikan dengan kegiatan KKN Mahasiswa selama kurang lebih 7 bulan. Metode yang digunakan mengadopsi berbagai teknik dalam pendekatan kualitatif dengan menekankan pada prinsip partisipatif sebagaimana digambarkan dalam tahapan kegiatan di table 1. Teknik observasi, wawancara, pemetaan social, FDG dilakukan selama kegiatan PKM ini berlangsung.

Secara umum tahapan kegiatan PKM terdiri dari tahapan persiapan Tim Riset dan pelatihan mahasiswa KKN, Sosialisasi Tim PKM dan KKN pada pemerintah Desa, desk study, perencanaan kegiatan, dan pelaksanaan kegiatan.

Gambar 4 Kegiatan PKM di Desa Cangkuang Wetan, Kecamatan Dayeuhkolot, Kabupaten Bandung

\begin{tabular}{|c|c|}
\hline & Persiapan Penelitian \\
\hline 19 April 2018 & $\begin{array}{l}\text { Diskusi Awal } \\
\text { Melakukan diskusi bersama terkait pembahasan fokus pelaksanaan kegiatan PPM }\end{array}$ \\
\hline \multirow[t]{2}{*}{25 April 2018} & $\begin{array}{l}\text { Desk Study } \\
\text { a. Review penelitian terdahulu terkait program stunting dan pengembangan kapasitas desa } \\
\text { b. Review data sekunder terkait program stunting dan pengembangan kapasitas desa }\end{array}$ \\
\hline & Penelitian Lapangan \\
\hline 16 Mei 2018 & $\begin{array}{l}\text { Observasi awal dan pengurusan perizinan } \\
\text { a. Melakukan kunjungan ke Kecamatan Dayeuhkolot dan Desa Cangkuang Wetan untuk } \\
\text { pengurusan perijinan. } \\
\text { b. Bertemu dengan Sekretaris Desa Cangkuang Wetan dan melakukan wawancara awal }\end{array}$ \\
\hline 20 Mei 2018 & $\begin{array}{l}\text { Observasi ke Desa Cangkuang Wetan } \\
\text { a. Melakukan kunjungan ke Pasar Minggu yang dilaksanakan di sekitaran kantor Desa } \\
\text { Cangkuang Wetan untuk mengamati kegiatan perekonomian desa } \\
\text { b. Melakukan observasi dan wawancara awal dengan pihak desa yang terlibat dalam } \\
\text { Eco-Village dan pengolahan sampah di desa } \\
\text { c. Melakukan observasi ke PAUD yang berada di belakang kantor desa }\end{array}$ \\
\hline 24 Mei 2018 & $\begin{array}{l}\text { Wawancara Kabupaten Bandung } \\
\text { Tim melakukan wawancara dengan Bagian Fisik Badan Perencanaan dan Pembangunan } \\
\text { Daerah (Bappeda) Kabupaten Bandung }\end{array}$ \\
\hline 7 Juni 2018 & $\begin{array}{l}\text { Diskusi anggota tim } \\
\text { Melakukan diskusi mengenai tahapan kegiatan selanjutnya terkait pelaksanaan kegiatan PPM }\end{array}$ \\
\hline 29 Sept 2018 & $\begin{array}{l}\text { Pengarahan awal kegiatan (briefing) PPM/KKNM } \\
\text { Melakukan perkenalan dan pengarahan mengenai kegiatan PPM/KKNM, melakukan } \\
\text { pembentukan kelompok, pembagian tugas dan rencana kerjabersama }\end{array}$ \\
\hline 1 Okt 2018 & $\begin{array}{l}\text { Literature Review } \\
\text { Melakukan pengkajian literatur dan data sekunder untuk lebih memahami isu stunting dan } \\
\text { lokasi PPM }\end{array}$ \\
\hline 5 Okt 2018 & $\begin{array}{l}\text { Kunjungan perdana ke Desa Cangkuang Wetan } \\
\text { Bertemu dengan Kepala Desa Cangkuang Wetan dan perkenalan mengenai kegiatan yang } \\
\text { akan dilaksanakan, yang kemudian dilanjutkan dengan survei sosial awal dan interaksi dengan } \\
\text { stakeholder lainnya yaitu PKK dan Kader Posyandu }\end{array}$ \\
\hline 6 Okt 2018 & $\begin{array}{l}\text { Kunjungan ke Desa Cangkuang Wetan } \\
\text { Melakukan identifikasi lapangan dan survei sosial di desa, yang sedang melaksanakan acara } \\
\text { Gerakan } 1001 \text { Anak Gemar Makan Ikan Tingkat Kecamatan Dayeuhkolot yang dilaksanakan di } \\
\text { Desa Cangkuang Wetan }\end{array}$ \\
\hline 13 Okt 2018 & $\begin{array}{l}\text { Kunjungan ke Desa Cangkuang Wetan } \\
\text { Melakukan identifikasi, pengumpulan data primer dan sekunder, serta survei sosial dengan } \\
\text { mengunjungi } 6 \text { dari } 12 \text { RW yang sudah ditentukan berdasarkan data sekunder secara berkala } \\
\text { (baru mengunjungi RW } 11 \text { dan Posyandu) }\end{array}$ \\
\hline 20 Okt 2018 & Workshop Bahan Social Mapping Desa Cangkuang Wetan \\
\hline 27 Okt 2018 & $\begin{array}{l}\text { Kunjungan ke Desa Cangkuang Wetan } \\
\text { Berkunjung ke } 6 \text { RW yaitu RW O1, RW } 03 \text {, RW } 06, \mathrm{RW} 07 \text {, RW } 09 \text {, dan RW } 12 \text { untuk melakukan } \\
\text { Social Mapping, serta mengikuti seminar di Posyandu Cangkuang Kulon }\end{array}$ \\
\hline 23 Nov 2018 & $\begin{array}{l}\text { Pelaksanaan Sosialisasi Isu Stunting dan Kesehatan Balita di Desa Cangkuang Wetan } \\
\text { Sosialisasi dilaksanakan dengan mengundang perangkat desa, ibu dan balita, serta perangkat } \\
\text { Posyandu, dengan memberikan pengarahan terkait percepatan penurunan stunting, } \\
\text { pentingnya kesehatan ibu dan balita, serta peran stakeholder lainnya dalam meningkatkan } \\
\text { kepedulian terhadap isu stunting. }\end{array}$ \\
\hline
\end{tabular}

Sumber: Diolah Tim PKM Desa Cangkuang Wetan 2018 


\section{HASIL DAN PEMBAHASAN}

\section{A. Pemetaan Sosial}

Desa Cangkuang Wetan merupakan desa yang terletak di Kecamatan Dayeuh Kolot, Kabupaten Bandung. Desa ini terdiri dari dua belas RW yang terdiri dari Kampung Cibedug Hilir, Kampung Cibedug Girang, Kampung Ciguriang Hilir, Kampung Ciguriang Girang, Kampung Cangkuang, Kampung Leuwimelang, Kampung Bojong Seureuh, Kampung Sekeandur, Kampung Bojong Citepus, Kampung Leuwimelang, Taman Cibaduyut Indah, dan Kampung Sukaluyu.

Lokasi desa yang berada di daerah selatan Kota Bandung menyebabkan sebagian daerah Desa Cangkuang Wetan menjadi langganan banjir saat musim penghujan. Hal ini menyebabkan banyaknya penyakit-penyakit bermunculan akibat banjir. Lingkungan yang dapat dikatakan jauh dari kata nyaman ini pula yang dapat mendorong peluang bayi lahir stunting semakin banyak di Desa Cangkuang Wetan. Oleh karena itu, dalam pemetaan sosial ini akan dikaji beberapa aspek yang berkaitan dengan balita atau bayi yang lahir dengan kondisi stunting. Berdasarkan diskusi dengan aparat desa, Secara umum Stakeholders yang terlibat dalam penanganan stunting di Desa Cangkuang Wetan terdiri dari: Perangkat Desa, BPD, Bidan Desa, Pengurus Posyandu, PKK, dan Ibu Balita.

Tabel 1 Hasil Pemetaan Stakeholder di Desa Cangkuang Wetan

\begin{tabular}{|c|c|c|c|c|}
\hline \multirow{2}{*}{ Who } & \multicolumn{3}{|c|}{ What } & \multirow{2}{*}{ How } \\
\hline & Have & Want & Need & \\
\hline PKK & $\begin{array}{l}\text { Ibu PKK di desa Cangkuang } \\
\text { Wetan aktif dalam berbagai } \\
\text { kegiatan pembangunan di } \\
\text { Desa, termasuk kegiatan } \\
\text { mencegah stunting. Dalam hal } \\
\text { ini peran aktif istri Sekretaris } \\
\text { Desa sangat penting, } \\
\text { mengingat terjadi kekosongan } \\
\text { jabatan Kepala Desa. Ketika } \\
\text { PKM dilakukan, Posisi } \\
\text { Kepala Desa dijabat oleh } \\
\text { Kabid Pemerintahan } \\
\text { Kecamatan karena Kades } \\
\text { mengundurkan diri terkait } \\
\text { pencalonannya menjadi } \\
\text { anggota DPRD untuk Pemilu } \\
\text { April 2019. }\end{array}$ & $\begin{array}{l}\text { Walaupun Desa Cangkuang } \\
\text { memiliki beberapa RW yang } \\
\text { kumur dengan jumlah } \\
\text { penduduk padat. Jumlah bayi } \\
\text { dan anak-anak yang mengidap } \\
\text { stunting di desa Cangkuang } \\
\text { Wetan berada dibawah ambang } \\
\text { batas. Sebagian besar ibu hamil } \\
\text { dan menyusui di desa } \\
\text { Cangkuang Wetan memiliki } \\
\text { kesadaran akan bahaya } \\
\text { Stunting dan mengetahui } \\
\text { pentingnya memberikan gizi } \\
\text { lebih baik lagi kepada anak- } \\
\text { anaknya. Hal ini terjadi karena } \\
\text { aktifnya kegiatan Posyandu } \\
\text { setiap bulan di semua RW. } \\
\text { Kegiatan sosialisasi stunting } \\
\text { sudah dilakukan, dan } \\
\text { melibatkan pihak luar Desa, } \\
\text { misalnya TNI, namun belum } \\
\text { ada program khusus dan } \\
\text { spesifik yang melibatkan PKK. }\end{array}$ & $\begin{array}{l}\text { Diadakannya sosialisasi } \\
\text { kepada ibu-ibu yang } \\
\text { memiliki bayi dan juga ibu } \\
\text { hamil untuk mencegah } \\
\text { terjadinya stunting di desa } \\
\text { Cangkuang Wetan. } \\
\text { Saat ini, sebagian besar ibu } \\
\text { yang memiliki Balita dan } \\
\text { tidak bekerja selalu aktif } \\
\text { mengikuti kegiatan } \\
\text { Posyandu. Hanya beberapa } \\
\text { RW yang ibu nya bekerja } \\
\text { dan kondisi keuangan mapan } \\
\text { tidak aktif di Posyandu. } \\
\text { Biasanya keluarha yang } \\
\text { lebhi sejahtera melakukan } \\
\text { vaksinasi oleh dokter umum. }\end{array}$ & $\begin{array}{l}\text { Mengharapkan } \\
\text { pemerintah terjun } \\
\text { langsung kelapangan } \\
\text { untuk melakukan } \\
\text { sosialisasi secara } \\
\text { langsung } \\
\text { kemasyarakat dan } \\
\text { dilakukan secara } \\
\text { berkelanjutan ( } \\
\text { terprogram) }\end{array}$ \\
\hline
\end{tabular}




\begin{tabular}{|c|c|c|c|c|c|}
\hline Bidan Desa & \multicolumn{2}{|c|}{$\begin{array}{l}\text { Mengadakan kelas ibu hamil } \\
\text { dan kelas ibu balita, juga } \\
\text { menyampaikan informasi } \\
\text { kepada masyarakat mengenai } \\
\text { pentingnya asupan gizi yg } \\
\text { baik selama kehamilan dan } \\
1000 \text { hari pertama kelahiran } \\
\text { bayi }\end{array}$} & $\begin{array}{l}\text { Penyuluhan tentang gizi yang } \\
\text { baik kepada masyarakat yang } \\
\text { dilakukan bersama oleh lintas } \\
\text { sektor. }\end{array}$ & $\begin{array}{l}\text { Kerjasama yang baik antar } \\
\text { lintas sektor, pembagian } \\
\text { PMT untuk bumil KEK, } \\
\text { balita BGM atau balita yang } \\
\text { pertumbuhannya kurang. }\end{array}$ & $\begin{array}{l}\text { Harus dilakukan } \\
\text { edukasi/ sosialisasi } \\
\text { yang menekankan } \\
\text { pada pentingnya } \\
\text { asupan gizi yang } \\
\text { baik, atau } \\
\text { pengolahan makanan } \\
\text { ya baik. Upaya dan } \\
\text { bantuan pemerintah } \\
\text { dalam menangani } \\
\text { kasus stunting juga } \\
\text { sangat perlu. }\end{array}$ \\
\hline \multirow[t]{5}{*}{$\begin{array}{l}\text { Pengurus } \\
\text { Posyandu }\end{array}$} & $\begin{array}{l}\text { RW } \\
06\end{array}$ & $\begin{array}{l}\text { Kader posyandu dan } \\
\text { ibu RT } 02 \\
\text { Rutin mengadakan } \\
\text { posyandu sekali } \\
\text { sebulan. ada acara } \\
\text { tahunan seperti } \\
\text { pembagian vit A dan } \\
\text { obat cacing. }\end{array}$ & $\begin{array}{l}\text { Menginginkan informasi } \\
\text { maupun sosialisasi yang lebih } \\
\text { merata mengenai penyakit- } \\
\text { penyakit yang sering } \\
\text { menyerang balita. karena kader } \\
\text { pun banyak yang tidak } \\
\text { memiliki latar belakang di } \\
\text { bidang kesehatan sehingga } \\
\text { pengetahuan tentang kesehatan } \\
\text { balita pun terbatas. } \\
\text { dan mengharapkan bantuan } \\
\text { tidak berhenti hanya untuk } \\
\text { balita yang kurang gizi saja, } \\
\text { karena di RW } 06 \text { ada beberapa } \\
\text { anak yang sudah berusia lebih } \\
\text { dari } 5 \text { tahun namun masih } \\
\text { memerlukan bantuan gizi dari } \\
\text { pemerintah. }\end{array}$ & $\begin{array}{l}\text { Ibu-ibu kader membutuhkan } \\
\text { edukasi yang lebih memadai } \\
\text { mengenai kesehatan balita } \\
\text { agar memudahkan kader } \\
\text { dalam menangani keluhan- } \\
\text { keluhan ibu-ibu yang datang } \\
\text { ke posyandu. }\end{array}$ & $\begin{array}{l}\text { Mengadakan } \\
\text { sosialisasi yang } \\
\text { menarik mengenai } \\
\text { isu-isu kesehatan } \\
\text { balita, khususnya } \\
\text { mengenai stunting. } \\
\text { Serta menyampaikan } \\
\text { aspirasi dari kader- } \\
\text { kader kepada yang } \\
\text { berwenang. }\end{array}$ \\
\hline & $\begin{array}{l}\text { RW } \\
07\end{array}$ & $\begin{array}{l}\text { Kader sekaligus ibu } \\
\text { RT }\end{array}$ & $\begin{array}{l}\text { Penyebaran informasi merata, } \\
\text { sosialisasi harus menarik dan } \\
\text { membuat masyarakat nyaman }\end{array}$ & $\begin{array}{l}\text { Penyebaran informasi } \\
\text { merata, edukasi stunting }\end{array}$ & $\begin{array}{l}\text { Sosialisasi stunting } \\
\text { dibuat menarik dan } \\
\text { masyarakat terhibur } \\
\text { (ada konsumsi) }\end{array}$ \\
\hline & $\begin{array}{l}\text { RW } \\
09\end{array}$ & $\begin{array}{l}\text { Kader sekaligus ibu } \\
\text { RW }\end{array}$ & $\begin{array}{l}\text { Tingkatkan fasilitas puskesmas, } \\
\text { dan penyuluhan mengenai } \\
\text { kesehatan }\end{array}$ & $\begin{array}{l}\text { Informasi mengenai } \\
\text { kesehatan harus digencarkan }\end{array}$ & Sosialisasi stunting \\
\hline & $\begin{array}{l}\text { RW } \\
12\end{array}$ & $\begin{array}{l}\text { Kader posyandu } \\
\\
\text { Untuk mengantisipasi } \\
\text { balita yang lahir } \\
\text { dengan keadaan } \\
\text { stunting, RW } 12 \\
\text { biasanya melakukan } \\
\text { pengecekan lebar } \\
\text { lingkar lengan } \\
\text { terhadap ibu hamil. } \\
\text { Informasi mengenai } \\
\text { isu-isu kesehatan } \\
\text { balita biasanya } \\
\text { disosialisasikan } \\
\text { kepada ibu-ibu RW } \\
12 \text { saat jadwal } \\
\text { posyandu. }\end{array}$ & $\begin{array}{l}\text { Informasi mengenai isu } \\
\text { stunting tidak diketahui oleh } \\
\text { semua kader, diharapkan } \\
\text { penyuluhan melalui isu ini } \\
\text { lebih ditingkatkan lagi. }\end{array}$ & $\begin{array}{l}\text { Ibu-ibu kader membutuhkan } \\
\text { edukasi yang lebih memadai } \\
\text { mengenai kesehatan balita } \\
\text { agar memudahkan kader } \\
\text { dalam menangani keluhan- } \\
\text { keluna ibu-ibu yang datang } \\
\text { ke posyandu. }\end{array}$ & $\begin{array}{l}\text { Mengadakan } \\
\text { sosialisasi yang } \\
\text { menarik mengenai } \\
\text { isu-isu kesehatan } \\
\text { balita, khususnya } \\
\text { mengenai stunting. } \\
\text { Serta menyampaikan } \\
\text { aspirasi dari kader- } \\
\text { kader ke pada yang } \\
\text { berwenang. }\end{array}$ \\
\hline & $\begin{array}{l}\text { RW } \\
12\end{array}$ & $\begin{array}{l}\text { Kader posyandu } \\
\text { Untuk mengantisipasi } \\
\text { balita yang lahir } \\
\text { dengan keadaan } \\
\text { stunting, RW } 12 \\
\text { biasanya melakukan } \\
\text { pengecekan lebar } \\
\text { lingkar lengan }\end{array}$ & $\begin{array}{l}\text { Informasi mengenai isu } \\
\text { stunting tidak diketahui oleh } \\
\text { semua kader, diharapkan } \\
\text { penyuluhan melalui isu ini } \\
\text { lebih ditingkatkan lagi. }\end{array}$ & $\begin{array}{l}\text { Ibu-ibu kader membutuhkan } \\
\text { edukasi yang lebih memadai } \\
\text { mengenai kesehatan balita } \\
\text { agar memudahkan kader } \\
\text { dalam menangani keluhan- } \\
\text { keluna ibu-ibu yang datang } \\
\text { ke posyandu. }\end{array}$ & $\begin{array}{l}\text { Mengadakan } \\
\text { sosialisasi yang } \\
\text { menarik mengenai } \\
\text { isu-isu kesehatan } \\
\text { balita, khususnya } \\
\text { mengenai stunting. } \\
\text { Serta menyampaikan } \\
\text { aspirasi dari kader- } \\
\text { kader ke pada yang }\end{array}$ \\
\hline
\end{tabular}




\begin{tabular}{|c|c|c|c|c|c|}
\hline & & $\begin{array}{l}\text { terhadap ibu hamil. } \\
\text { Informasi mengenai } \\
\text { isu-isu kesehatan } \\
\text { balita biasanya } \\
\text { disosialisasikan } \\
\text { kepada ibu-ibu RW } \\
12 \text { saat jadwal } \\
\text { posyandu. }\end{array}$ & & & berwenang. \\
\hline \multirow[t]{5}{*}{$\begin{array}{l}\text { Ibu - ibu } \\
\text { Balita }\end{array}$} & $\begin{array}{l}\text { RW } \\
06\end{array}$ & $\begin{array}{l}\text { Ibu yang memiliki } \\
\text { balita rutin } \\
\text { memeriksakan } \\
\text { anaknya ke posyandu } \\
\text { untuk menimbang } \\
\text { berat badan. } \\
\text { kondisi ekonomi } \\
\text { yang kurang } \\
\text { memadai karena } \\
\text { hanya seorang asisten } \\
\text { rumah tangga }\end{array}$ & $\begin{array}{l}\text { Menginginkan informasi yang } \\
\text { jelas mengenai kondisi bayinya } \\
\text { karena biasanya selama ini } \\
\text { jarang diberi informasi } \\
\text { mengenai isu-isu tentang } \\
\text { kesehatan balita. } \\
\text { Sering diadakan bantuan } \\
\text { pemerintah dalam memenuhi } \\
\text { gizi balita }\end{array}$ & $\begin{array}{l}\text { Ibu-ibu balita sangat } \\
\text { membutuhkan pendidikan } \\
\text { tentang pentingnya } \\
\text { memperhatikan gizi dan } \\
\text { kesehatan balita. }\end{array}$ & $\begin{array}{l}\text { Mengadakan } \\
\text { sosialisasi mengenai } \\
\text { isu-isu mengenai } \\
\text { kesehatan balita, } \\
\text { khususnya isu } \\
\text { stunting dan } \\
\text { memberikan bantuan } \\
\text { gizi seperti MPASI }\end{array}$ \\
\hline & $\begin{array}{l}\text { RW } \\
\mathbf{0 7}\end{array}$ & $\begin{array}{l}\text { Ibu yang memiliki } \\
\text { anak kecil dan sedang } \\
\text { hamil }\end{array}$ & $\begin{array}{l}\text { Ingin mengetahui lebih dalam } \\
\text { lagi mengenai stunting karena } \\
\text { khawatir }\end{array}$ & Sosialisasi stunting & $\begin{array}{l}\text { Sosialisasi stunting } \\
\text { harus mudah } \\
\text { dipahami oleh } \\
\text { seluruh kalangan } \\
\text { masyarakat }\end{array}$ \\
\hline & $\begin{array}{l}\text { RW } \\
09\end{array}$ & Ibu & Tingkatkan fasilitas puskesmas & $\begin{array}{l}\text { Pemerataan informasi yang } \\
\text { didapat Kader dengan } \\
\text { masyarakat }\end{array}$ & $\begin{array}{l}\text { Sosialisasi stunting } \\
\text { harus dapat } \\
\text { disebarluaskan }\end{array}$ \\
\hline & $\begin{array}{l}\text { RW } \\
12\end{array}$ & $\begin{array}{l}\text { Ibu yang memiliki } \\
\text { balita } \\
\text { Tidak terlalu rutin ke } \\
\text { posyandu karena } \\
\text { mengajar di SMP } \\
\text { swasta. } \\
\text { Memperhatikan gizi } \\
\text { balita dengan } \\
\text { memberikan makanan } \\
\text { pendamping ASI } \\
\text { untuk melengkapi } \\
\text { gizi dari sang anak }\end{array}$ & $\begin{array}{l}\text { Menginginkan sosialisasi } \\
\text { mengenai bahaya stunting lebih } \\
\text { ditingkatkan karena ibu ini } \\
\text { mengatakan belum mengetahui } \\
\text { mengenai isu stunting } \\
\text { sebelumnya serta peran dari } \\
\text { posyandu beserta puskesmas } \\
\text { untuk agar dapat mencegah } \\
\text { adanya balita dengan kondisi } \\
\text { stunting di desa cangkuang } \\
\text { wetan }\end{array}$ & $\begin{array}{l}\text { Ibu-ibu balita sangat } \\
\text { membutuhkan pendidikan } \\
\text { tentang pentingnya } \\
\text { memperhatikan gizi dan } \\
\text { kesehatan balita. }\end{array}$ & $\begin{array}{l}\text { Mengadakan } \\
\text { sosialisasi mengenai } \\
\text { isu-isu mengenai } \\
\text { kesehatan balita, } \\
\text { khususnya isu } \\
\text { stunting dan } \\
\text { memberikan bantuan } \\
\text { gizi seperti MPASI }\end{array}$ \\
\hline & $\begin{array}{l}\text { RW } \\
\mathbf{0 3}\end{array}$ & $\begin{array}{l}\text { Ibu yang memiliki } \\
\text { balita }\end{array}$ & $\begin{array}{l}\text { Pekerjaan yang layak sehingga } \\
\text { memiliki banyak waktu untuk } \\
\text { mengasuh dan mendidik anak. }\end{array}$ & $\begin{array}{l}\text { Penyebaran informasi terkait } \\
\text { stunting yang melibatkan } \\
\text { banyak pihak, dalam hal ini } \\
\text { tidak hanya ibu yang } \\
\text { memiliki balita dan ibu } \\
\text { hamil saja tetapi juga mertua } \\
\text { dan suami (yang turut } \\
\text { mengasuh anak). }\end{array}$ & $\begin{array}{l}\text { Pengadaan } \\
\text { sosialisasi di hari } \\
\text { libur (kerja) dan } \\
\text { pemberian materi } \\
\text { yang menarik. } \\
\text { Adanya "hadiah" } \\
\text { dalam pelaksaan } \\
\text { sosialisasi. }\end{array}$ \\
\hline
\end{tabular}

\section{B. Analisis Hasil Lapangan dan Kegiatan Sosialisasi}

Berdasarkan social mapping yang telah dilakukan mahasiswa dan Tim PKM terhadap stakeholder pembangunan desa yang memiliki peran dalam menunjang kondisi kesehatan masyarakat salah satunya kesehatan balita. Isu stunting dianggap menjadi hal penting karena tidak hanya berdampak pada tinggi badan (kerdil), namun berpengaruh terhadap pertumbuhan otak, kondisi fisik maupun mental balita. Untuk mencapai hasil yang diinginkan tidak hanya tugas Bidan, Posyandu ataupun PKK, namun stakeholder pembangunan desa berperan dalam membantu perbaikan kualitas pertumbuhan balita. Hal ini juga didukung Gubernur Jawa Barat 
dengan pengalokasian program peningkatan gizi ibu dan balita dari Dana Desa serta dukungan dari dinas terkait. Tim PKM UNpad bersama dengan mahasiswa KKN yang ditempatkan di Desa Cangkuang Wetan melaksanakan kegiatan Sosialisasi yang diintegrasikan dengan aktivitas rutin kader Posyandu bersama dengan Ibu Balita. Tim juga terlibat aktif dalam membantu proses persiapan program Gerakan 1001 Anak Gemar Makan Ikan di Tingkat Kecamatan Dayeuh Kolot.

Gambar 5. Sosialisasi dengan Stakeholder Pembangunan Desa

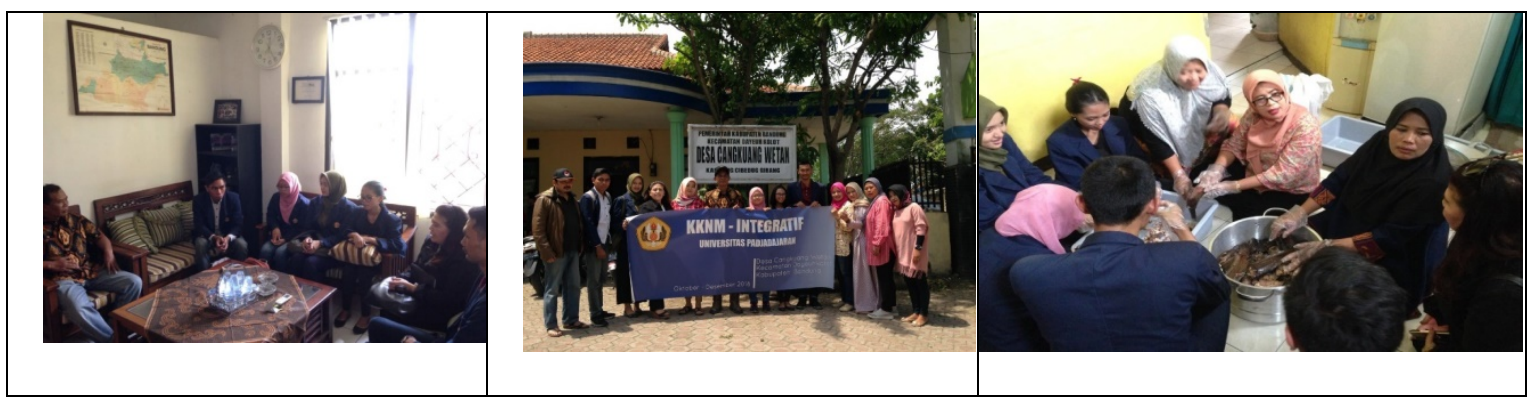

Gambar 6. Kegiatan identifikasi, pengumpulan data primer dan sekunder, serta survei sosial di Desa Cangkuang Wetan

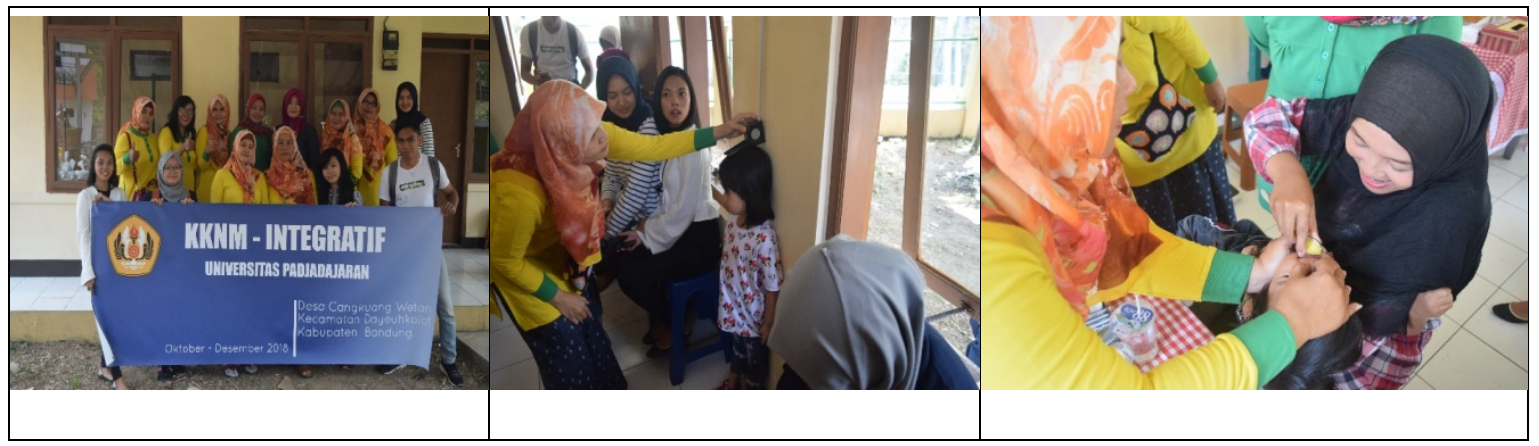

Gambar 7. Partisipasi Aktif dalam acara Gerakan 1001 Anak Gemar Makan Ikan Tingkat Kecamatan Dayeuhkolot yang dilaksanakan di Desa Cangkuang Wetan

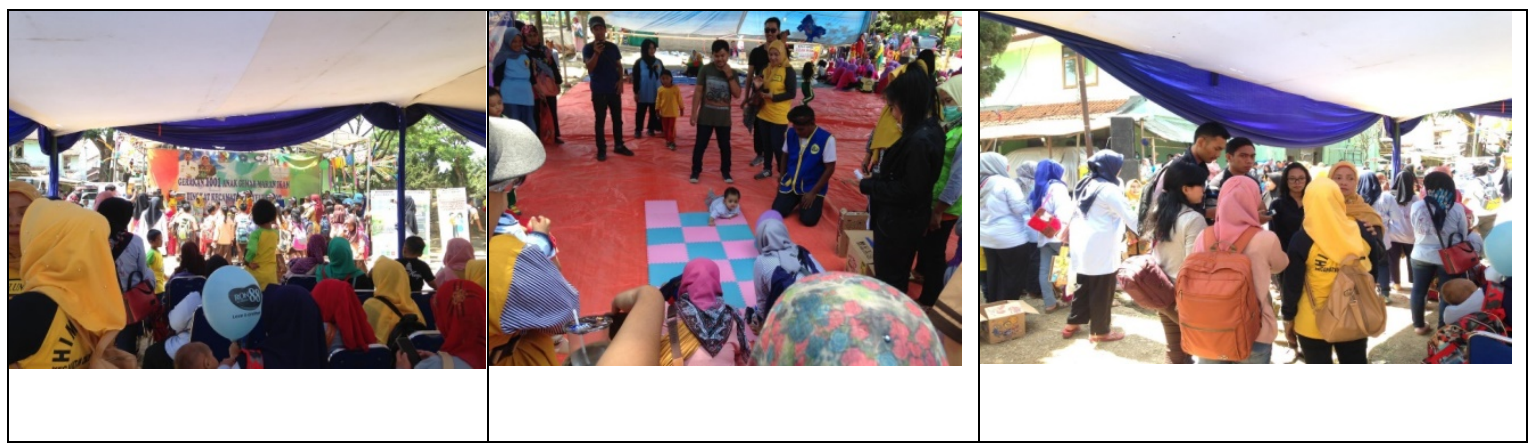




\section{SIMPULAN}

Kegiatan PKM di Desa Cangkuang Wetan secara khusus difokuskan pada upaya mencegah stunting dilaksanakan Perubahan konsep KKN Universitas Padjadjaran bertujuan untuk menyelaraskan proses Tri Dharma Perguruan Tinggi dengan apa yang menjadi kebutuhan masyarakat sebagai bentuk respon perguruan tinggi. Program-program yang dibawa perguruan tinggi ke dalam masyarakat diharapkan dapat menjawab kebutuhan nyata dalam masyarakat. Dengan adanya peningkatan performa riset di Universitas Padjadjaran dan dengan pemikiran bahwa PPM adalah downstreaming dari kegiatan riset dosen, maka pelibatan mahasiswa dalam kegiatan pengabdian dosen ini akan menjadi tambahan energi bagi Universitas. Selain dapat berkontribusi dalam kegiatan pengabdian masyarakat, mahasiswa juga mendapatkan kesempatan untuk mendapatkan pembelajaran dari kegiatan yang berlangsung, baik dari dosen maupun dari masyarakat itu sendiri. Dalam kegiatan PKM ini.

\section{UCAPAN TERIMAKASIH}

Terima kasih tim PPM sampaikan kepada Rektor Universitas Padjadjaran Prof. Dr. Med. Tri Hanggono Achmad, dr atas skema riset Hibah Internal Unpad yang mendukung riset dan PPM yang dilaksanakan dalam semester genap 2018. Kepala Desa dan aparat Desa Cangkuang Wetan, Pegawai Puskesmas, Bidan, Kader POsyandu dan Ibu Balita yang terlibat dalam kegiatan ini. Mahasiswa Unpad berbagai fakultas yang ditempatkan di Desa Cangkuang Wetan.

\section{DAFTAR PUSTAKA}

Black, R. E., Victora, C. G., Walker, S. P., Bhutta, Z. A., Christian, P., De Onis, M., ... Uauy, R. (2013). Maternal and child undernutrition and overweight in low-income and middle-income countries. The Lancet. https://doi.org/10.1016/S0140-6736(13)60937-X

Dehghan, M., Akhtar-Danesh, N., Merchant, A., Wang, Y. F., Lobstein, T., Sakamoto, N., ... Eckersley, R. (2014). Socioeconomic status and obesity in adult populations of developing countries: A review. Social Science and Medicine, 1(1), 1-384. https://doi.org/1 Desember 2013

Firman, T. (2002). Urban development in Indonesia, 1990-2001: From the boom to the early reform era through the crisis. Habitat International, 26(2), 229-249. https://doi.org/10.1016/S0197-3975(01)00045-5

Gross, R. (2002). Food and nutrition security in poverty alleviation: Concepts, strategies, and 
experiences at the German Agency for Technical Cooperation. Asia Pacific Journal of Clinical Nutrition, 11, S341-S347. https://doi.org/10.1046/j.1440-6047.11.s1.8.x

Howell-Moroney, M. (2008). The Tiebout hypothesis 50 years later: Lessons and lingering challenges for metropolitan governance in the 21st century. Public Administration Review, 68(1), 97-109. https://doi.org/10.1111/j.1540-6210.2007.00840.x

Hudalah, D., Winarso, H., \& Woltier, J. (2007). Peri-urbanisation in East Asia - A new challenge for planning? INTERNATIONAL DEVELOPMENT PLANNING REVIEW, 29(4), 503-519.

Prendergast, A. J., \& Humphrey, J. H. (2014). The stunting syndrome in developing countries. Paediatrics and International Child Health. https://doi.org/10.1179/2046905514Y.0000000158

Sekretariat wakil presiden republik indonesia. (2017). 100 Kabupaten/Kota Prioritas Untuk Intervensi Anak Kerdil (Stunting). 100 Kabupaten/Kota Prioritas Untuk Intervensi Anak Kerdil (Stunting). https://doi.org/10.15713/ins.mmj.3

Tim Nasional Percepatan Penanggulangan Kemiskinan Republik Indonesia. (2018). Gerakan Nasional Pencegahan Stunting dan Kerjasama Kemitraan Multi Sektor.

Van De Poel, E., Hosseinpoor, A. R., Speybroeck, N., Van Ourti, T., \& Vega, J. (2008). Socioeconomic inequality in malnutrition in developing countries. Bulletin of the World Health Organization. https://doi.org/10.2471/BLT.07.044800 